\title{
The effect of qualitative differences in audio stimuli and backgrounds in instrumental escape conditioning
}

DALE M. ATRENS, RUTGERS UNIVERSITY CAMILLE E. WAGNER, HOLLINS COLLEGE

Escape conditioning to 2 audio stimuli (buzzer or white noise) was investigated in a running wheel under 2 audio background conditions (buzzer or white noise). Audio aversiveness was found to be dependent not upon a particular stimulus or background but on a specific relation between the two. That is, while a buzzer stimulus out of a whitenoise background produced a high level of escape responding, neither the converse situation or either white noise out of white noise or buzzer out of buzzer conditions produced escape behavior. The implications of these data for a broader explanation of audio aversiveness are discussed.

The qualitative characteristics of the stimuli used in conditioning have received little attention. Bolles \& Atrens (submitted) have demonstrated large and significant effects of both quantity (shock intensity) and quality (the way in which shock is scrambled) of the US in aversive conditioning. In addition, Myers (1959, 1962, 1964) has demonstrated the importance of qualitative characteristics of the CS in a Skinnerbox training situation. More specifically, Myers has shown that a buzzer CS produced better avoidance learning than a 4000-cps tone $(1962,1964)$ or a blast of white noise (1964) of equal physical intensity. Myers has subsequently (1965) attributed these effects as being, at least partially, due to the higher aversiveness of a buzzer when compared to white noise or pure tones of the same physical loudness. However, this approach merely substitutes one question for another. In this case the substitute is why does this aversiveness discrepancy occur?

A partial solution to this paradox may be inferred from studies by Hoffman \& Fleshler (1963) and Hoffman \& Searle (1965). These authors have demonstrated that uniform concurrent background audio stimulation increases the aversiveness (as measured by startle eliciting properties) of loud, short duration sounds. If their results have any generality, a brief, loud white noise should be more aversive coming out of a white-noise background than from one of a more irregular nature (e.g., a buzzer background). On the other hand, Perkins (1953) cites data from Bragiel (1953) which indicates that stimulus intensity effects may be due to stimulus-background contrast. This leads to predictions opposite to those drawn from Hoffman et al $(1963,1965)$ in the case of the two white-noise stimulus conditions mentioned above. However, they both would predict a buzzer stimulus to be more aversive when presented against a whitenoise background than when the background was more irregular (e.g., a buzzer), although for different reasons.

The primary purpose of this study was to determine the influence of concurrent background audio stimulation on the aversiveness of two audio stimuli in a sensitive, operant escape conditioning situation. The design used also permitted the evaluation of two different approaches to explaining this effect.

\section{Subjects}

The Ss were 25 experimentally naive SpragueDawley rats, weighing between $180-200 \mathrm{gm}$ at the start of the experiment.

\section{Apparafus}

The apparatus was a Wahmann activity wheel, 14 in. in diameter. Wheel turn responses were recorded on an integrating counter. The buzzer was a Liberty (AC) and the white-noise generator was a Grason-Stadler, model $901 \mathrm{~B}$.

The $50 \mathrm{~dB}$ background was recorded by a V-M model 722 stereo-tape recorder on an endless tape loop. Sound intensity was measured by a General Radio, type 1551-C sound level meter set to frequency response curve "C."

The activity wheel, buzzer, and speakers for both the tape recorder and the white-noise generator were mounted in a heavily sound insulated room in a small, free standing building. The programming equipment was located in another part of the laboratory.

\section{Procedure}

Ss were randomly assigned to (four experimental and one control) groups. Group B-W was presented with a buzzer stimulus and a white-noise background; group B-B, buzzer stimulus out of buzzer background; group $W-W$, white-noise stimulus out of white-noise background; group W-B, white-noise stimulus out of a buzzer background. A control group was employed to determine the operant level in this wheel. They received no stimulus and merely had a continuous $50 \mathrm{~dB}$ white-noise background. The demonstrated lack of aversiveness or activating effect of sounds of the low intensity of our background (Myers, 1965) precluded the running of a no-stimulus, buzzer background group to determine an alternate operant level.

Each experimental $S$ was placed in the wheel whereupon, after 15 sec., a $70 \mathrm{~dB}$ stimulus (buzzer or white noise) was presented against a constant background of either buzzer or white noise. The US remained 


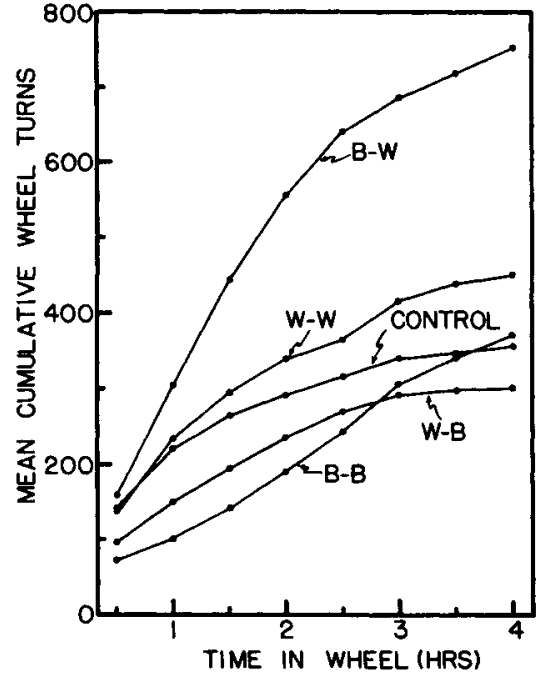

Fig. 1. Mean cumulative wheel turns under the four experimental and one control conditions over the four hr. test period.

on until S made one wheel turn which would terminate it for $15 \mathrm{sec}$. The US was presented every $15 \mathrm{sec}$. with no avoidance, only escape, being possible. All Ss, experimental and control, were run for four hours. One $S$ from each of the five groups was run in each of the five running periods starting at 8:00 a.m. and ending at 4:00 p.m.

\section{Results}

Since one $S$ in each group in the time slot, noon4:00 p.m., fell asleep within a few minutes, the data presented in Fig. 1 are based on $n=4$. The mean cumulative number of responses for all experimental groups were compared to that of the control group by Dunnett's test (Winer, 1962). This test indicates that the only experimental manipulation which produces a result significantly different from the operant level control group is when the buzzer stimulus comes out of a white-noise background $(t=2.51, p<.05)$.

\section{Discussion}

These data demonstrate that the aversiveness of low intensity audio stimuli is dependent upon both the quality of the stimulus itself and that of the concurrent audio background.

The predictions drawn from Hoffman et al's (1963, 1965) data and from Perkins' (1956) data concerning the buzzer stimulus were vindicated. That is, the buzzer was more aversive (in terms of eliciting more escape behavior) when it came from a white-noise background than from a buzzer background. However, since no appreciable escape behavior took place under either white-noise stimulus condition, overall, each set of predictions leads to one right and one wrong answer.

More important than the theory validating function of these data, however, is the fact that they indicate that "loudness" is not enough to explain the aversiveness of audio stimuli. It seems apparent then, that while loudness may account for within-stimulus aversiveness effects, a second (or however many more there are) parameter determines aversiveness between qualitatively different sounds.

Myers (1965) has demonstrated that the unusually high aversiveness of the buzzer is not due to its high frequencies. Perhaps, it is the frequency and amplitude complexity of the buzzer which make it more aversive. This could be demonstrated through systematic, progressive reconstructions of a buzzer-type sound. This procedure, which would amount to a psychophysical factor-analysis, seems like a promising avenue for further research.

While this analysis by no means exhausts the possible explanations for the unusual aversiveness of buzzer stimuli, it may indicate the extent and complexity of the problem. A solution to this problem would provide not only immediate technological information concerning the behavioral effects of stimuli commonly used in appetitive and aversive conditioning but it would also find applicabllity in broader theories of audition.

\section{References}

Bolles, R. C., \& Atrens, D. M. Some behavioral effects of inescapable shock (submitted).

Bragiel, R. M. The effects of absolute stimulus intensity and stimulus contrast on response strength. Unpublished master's thesis, Kent State University, 1953, cited in Perkins, 1953.

Hoffman, H. S., \& Fleshler, M. A. Startle reaction; modification by background stimulation. Science, 1963, 141, 928-930.

Hoffman, H. S., \& Searle, J. L. Acoustic variables in the modification of the startle reaction in the rat. J. comp. phy siol. Psychol., 1965, 60, 53-58.

Myers, A. K. Avoidance learning as a function of several training conditions and strain differences in rats. $J$. comp. physiol. Psychol., 1959, 52, 381-386.

Myers, A. K. Onset vs. termination of stimulus energy as the CS in avoidance conditioning and pseudoconditioning. $J$. comp. physiol. Psychol., 1960, 53, 72-78.

Myers, A. K. Effects of CS intensity and quality in avoidance conditioning. J. comp. physiol. Psychol., 1962, 55, 57-61.

Myers, A. K. Discriminated operant avoidance learning in Wistar and G-H rats as a function of the type of warning stimulus. $J$. comp. phy siol. Psychol., 1964, 58, 453-455.

Myers, A. K. Instrumental escape conditioning to a low-intensity noise by rats. J. comp. physiol. Psychol., 1965, 60, 82-87.

Perkins, C. C., Jr. The relations between conditional stimulus intensity and response strength. J. exp. Psychol., 1953, 46 225-231.

Winer, B. J. Statistical principles in experimental design. New York: McGraw-Hill, 1962. 